\title{
Individual knowledge sharing behavior in dynamic virtual communities: the perspectives of network effects and status competition
}

Shenglei $\mathrm{Pi}^{i^{*}}$ and Weining $\mathrm{Cai}^{2}$

* Correspondence: pishenglei@126.com

${ }^{1}$ School of Management, Guagnzhou University, Guangzhou, Guangdong 510410, China Full list of author information is available at the end of the article

\begin{abstract}
Purpose: While most literature concerning knowledge sharing examines it as an organizational method for innovation and value creation, this paper considers online knowledge sharing as an individual behavior decision embedded in a virtual community. We attempt to explore which sharing behavior can help individual participants gain a better position in an online community, improving social status, reputation, and other social networking interests.
\end{abstract}

Design/methodology/approach: We collected and measured the knowledge sharing activities and discussion from a Chinese online expertise knowledge network in Business Management Consulting. We tested the mediating effects of the sharing behavior of the major members of the online knowledge network on members' status (network centrality) in different time units (days).

Findings: In a dynamic virtual community, the direct result of knowledge sharing behavior is reflected in the individual status position (the degree of node centrality). At the same time, individual knowledge sharing behavior has an "inertia effect": individual prior status (the degree of node centrality) affects current knowledge sharing behavior, while current knowledge sharing behavior affects current status in the knowledge network, forming an inertial circuit between personal behavior and network status.

Originality/value: We expound the theory of individual knowledge sharing in the context of an inter-person dynamic virtual community; we provide action "strategies" for individual knowledge sharing behavior choice, for better understanding the nature of individual knowledge behavior, and we also propose and test the "inertia effect" of knowledge sharing behavior and the knowledge network, and demonstrate the theory of network effects from an individual perspective.

Keywords: Dynamic virtual community, Individual knowledge sharing, Network effect, Competition

\section{Introduction}

Knowledge sharing was initiated as a method of knowledge management (Kang, et al., 2017) and organizational learning (Almeida and Soares, 2014), especially in the context of innovative process management (Zhou and $\mathrm{Li}, 2012$ ), or supply chain management (Cai, et al., 2013). Most literature on knowledge sharing aims to examine whether 
knowledge sharing can improve organizational performance in innovation and learning and if so, how (Ritala, et al., 2015). While the development of social network technology (Jiang, 2015) and the emergence of the sharing economy (Wang et al., 2011) in recent years might make knowledge sharing a common and crucial method for individuals in individual learning, social networking, and even career improvement (Chen and Hung, 2010). Especially in online knowledge networks, knowledge sharing is mainly for catching "eyeballs" and turning it into actual economic and social benefits (Qiu and Wang, 2011). Individual knowledge sharing actions are not just for knowledge learning, but also for inter-personal competition, cooperation, self-reputation, or even free-rider experiences (Liao et al., 2013). Therefore revealing the mechanism of individual knowledge sharing behavior is not only important for knowledge management and organizational learning in a sharing economy but also helps to understand and establish knowledge sharing networks while encouraging participants to share. Moreover, most scholars examine knowledge sharing in a static context or knowledge network (Saifi et al., 2016; Reinholt and Foss, 2011), with only a few building dynamic models of knowledge sharing from the perspective of network effects (Gong, 2011; Butts, 2011).

Individual knowledge sharing in the sharing economy has turned out to be more likely an individual behavior, rather than just an organizational decision. Also, the decision to engage in knowledge sharing behavior is operating under the dynamic structure of the entire knowledge network. This study aims to explore the mechanism between the character of individual online knowledge sharing behavior and individual network status, to help individual participants gain more social and economic benefits by choosing effective sharing behavior. According to the theory of network effects, one can have more network connections with fewer costs when one gains critical mass (Economides and Himmelberg, 1995). Though network effect theory indicates that the scale of participants will help the entire network gain alternative value and improve performance (Arroyo, 2007), individual choice and decisions taken under the network effect are still a blind spot. More connections bring more social capital and other benefits for the individual, and encourage more sharing behavior from such participants. Therefore if one received the most attention and response in the knowledge network in the past, it is easy to predict that he/she will deploy similar sharing behaviors in the future.

One major task of this paper is to test whether the "inertia effects" mentioned above, which can make individual knowledge sharing behavior enhance online status, exist, given that the structure of and participants in online knowledge networks are dynamic. Also, this paper attempts to explore the character of sharing behavior to help individual participants to be more effective when sharing knowledge.

In this study, we measured an online expertise knowledge community, a QQ group, capturing and calculating its dynamics each day. Then we tested the mediating effects of the sharing behavior of its major members on the members' status (network centrality) in different time zones (days). The major contribution of our study focuses on knowledge sharing. This study supplies theoretical indicators for knowledge sharing under cross-hierarchy, individual sharing behavior. Secondly, this study helps to explore whether there is an "inertia effect" of knowledge sharing in a dynamic online knowledge network, and whether it impacts dynamic behavior decisions on knowledge sharing. Thirdly, our study helps to understand the network effect from individual 
perspectives, by revealing that sharing behavior which attracts responses will help network status growth, and collectively the growth of the entire network.

In the next section, we propose hypotheses based on literature reviews of both network effects theory and knowledge sharing. The online knowledge sharing sample choice and measurement and variable designation are reported in Research design: Network analysis of an online community from the Chinese consulting industry section. With empirical results reported in Analysis result section, we have our discussion and final conclusion in Discussion and conclusion section.

\section{Theory and hypotheses}

Knowledge sharing in dynamic virtual communities: A literature review

Knowledge sharing behavior is a two-way interactive exchange activity around either explicit or tacit (Yong, et al., 2013) knowledge in a work team (Weinberg, 2015), organization (Barão, et al., 2017), inter-firm network (Gupta and Polonsky, 2014), or a community (Liao et al., 2013). Knowledge sharing helps with cooperation with others, passing on knowledge to others, and searching and acquiring knowledge from others (Zhang et al., 2014). Though initiated in the context of a certain organization, or an inter-organization cooperation such as a supply chain (Cai, et al., 2013), scholars have found that most knowledge sharing behavior in recent years occurs in inter-personal communities such as employee communities (Yong, et al., 2013). With the development of internet technology and virtual social networks, many such communities are virtual (Olaisen and Revang, 2017; Liao et al., 2013).

Hendriks (2015) defined knowledge sharing in a virtual community as the sharing of community-related information, ideas, suggestions, and expertise among individuals (Yu et al., 2010). Factors of knowledge sharing behavior have been studied at different levels and from different perspectives, including the cultural characteristics, environmental factors, motivational factors, interpersonal and team characteristics, individual characteristics, etc. (Wang et al., 2011). More than half the studies focused on the individual level (He and Wei, 2009), such as personal intrinsic and extrinsic motivations (Lin, 2007), trust (Hsu et al., 2007) and psychological security (Zhang et al., 2010), individual motivation (Wasko and Faraj, 2005), personality traits (Organ and Lingl, 1994) and so on. Other research highlighted organizational levels, such as social capital (Nahapiet and Ghoshal, 1998; Tsai and Ghoshal, 1998), social networks (Xue, 2011), social cognition (Hsu et al., 2007), or organizational climate (Bock et al., 2005). Particularly when discussing virtual communities, social network theory, community structure and an individual's position in a network (Zhou et al., 2014) are also be found to be factors influencing knowledge sharing behavior. While scholars have identified a number of factors impacting knowledge sharing, we still lack understanding about knowledge sharing actions or patterns especially as related to providers, receivers, and context.

Knowledge has been acknowledged as a competitive advantage for those who possess it in the right place and at the right time (Lorange, 1996; Bij et al., 2003). The competitive advantage of holding special knowledge (Yang and Wu, 2008) may be reduced by sharing. Thus simultaneous cooperation and competition affect knowledge sharing (Loebecke et al., 1999). Tsai (2002) and Luo et al. (2006) investigated the inter-dependent impact of competition and cooperation on knowledge sharing behaviors, whereas Lin (2007), Avital 
and Singh (2007), and Lin et al. (2010) investigated the separate impacts of cooperation and competition on organizational outcomes. Most literature about the competitive and cooperative effects of knowledge sharing examines it in the context of cross-function, which is still intra-organization. Few scholars have discussed the competitive effects of knowledge sharing in an inter-person virtual community or explored the rules of knowledge sharing behavior for individual advantage in the community.

Social network theory is one of the foundations for analyzing knowledge sharing in virtual communities (Saifi et al., 2016). However, prior literature has analyzed the knowledge network as static and discussed knowledge sharing under such static network contexts. With many calls for more longitudinal studies to complement this work (Bock et al., 2005; Wei et al., 2009; Yang and Farn, 2009), only a few have tested the relationship between previous and current knowledge sharing behavior (Lin et al., 2014). However, scholars still ignore the dynamics of the structure of a knowledge network, and also that the dynamics of participants in the knowledge network can also affect sharing behavior.

\section{Network effects and competitive decision-making in virtual communities}

The term "network effect" (network externalities) refers to the increased value of a product (technology, good or service) as the number of users of this product increases (Arroyo, 2007). Knowledge sharing and transfer in a virtual community is a kind of knowledge network (Chen and Hung, 2010). The network effect of a knowledge network refers to the consolidation of specific knowledge when the network scale increases. Network externalities in a knowledge network reflect that the contribution of specific knowledge to other network users will enhance, and the dilution of learning costs reduce, when more members join the knowledge network (Katz and Shapiro, 1985; Torrent-Sellens, 2015).

We consider a virtual community to also be formed as a knowledge network, with network effects. Though the participants in knowledge sharing and exchange are dynamic over time, individuals with prior higher centrality will be the subject of more social cognition from other community members, and have more knowledge or information followers in the current network. Also, as an entire network, more new members will be attracted because of the network effects, and new members generally have higher opportunities to make new connections to members with prior higher centrality. Therefore we propose hypothesis $\mathrm{H} 1$ :

H1: In a virtual community, the prior centrality of the individual has a positive effect on current centrality.

Under the inter-organization context, participants in a virtual community mostly do so for the purposes of himself/herself and cooperate under Gaming and Competition (Gupta and Polonsky, 2014). Therefore, building advantages in a virtual community is the priority objective of individual action choice for knowledge sharing. For gaining the advantage in such knowledge networks, centrality in the network should be the target of each knowledge sharing behavior. According to social network theory (Park and Lee, 2014), there are two major knowledge sharing behaviors to achieve higher centrality: frequency and originality of knowledge sharing.

Firstly, the frequency of knowledge sharing behavior may help to attract more eyeballs for individuals in the knowledge network. For example, people usually identify the opinion 
leaders in a community through the intensity of information and knowledge released (Yoo and Alavi, 2004). Moreover, the frequency of knowledge sharing behavior will generate more feedback and discussion, so as to promote information and knowledge exchange (Koh, et al., 2007) and transfer in the knowledge network (Ma et al., 2006). Naturally, this will increase the centrality of individual nodes in the dynamic knowledge network.

H2a: In a dynamic virtual community, the current frequency of knowledge sharing has a positive effect on current individual centrality.

Secondly, the feedback from the original knowledge sharing must be positive because all members, including the "silencer" and "free rider", are looking forward to original "high-value knowledge sharing". In order to get more original knowledge, the members of the community will try to endow the original sharing behavior with "positive feedback", so as to encourage similar behavior (Wang, 2014). Therefore, individuals are more likely to be in a position close to the center when they share original knowledge with others in the dynamic knowledge network.

H2b: In a dynamic virtual community, the current originality of knowledge sharing has a positive effect on current individual centrality.

\section{Previous network position and current sharing behavior}

Considering the virtual community as a knowledge network, the position of participants is found to determine their knowledge sharing. A growing body of research has found that possessing a central network position predicts more knowledge sharing (e.g., Anderson, 2008; Burt, 1992; Freeman, 1979; Tsai, 2001). Those by virtue of their network position have privileged knowledge-sharing opportunities and thereby access to new knowledge (Wasserman and Faust, 1994). Anderson (2008) showed that a central network position is positively related to the amount and diversity of the knowledge that is acquired by an employee, and Tsai (2001) argued that organizational units that are centrally positioned in their intra-organizational networks engage in more knowledge sharing and therefore are more innovative than units that are low in network centrality. Research on advice networks has similar findings. Sparrowe et al. (2001) found that individuals with a central position in an organization's advice network exhibit higher levels of both in-role and extra-role performance. Reinholt and Foss (2011) demonstrated that in an employee community, knowledge acquisition and provision is higher when an employee's network centrality is high.

One of the features of an online knowledge network is that the actual participants in knowledge sharing are dynamic, whereby each member is free to decide whether or not to participate in specific knowledge sharing and discussion at a certain time. Longitudinal research of organizational knowledge sharing by Lin et al. (2014) found that learning the effect of the individual in the previous phase has a partial mediating effect between previous and current knowledge sharing behavior. The decision to engage in knowledge sharing behavior is influenced by previous social stimulation and feedback (Li, 2005). If one had succeeded in previous sharing behavior decisions, he (she) will follow the path of previous sharing behavior, as suggested by network effects theory (Arroyo, 2007) and path dependency (Mishina et al., 2012). Therefore, a previous network position can be regarded as the result of previous knowledge sharing behavior, while a current behavior decision will be determined by the previous network position. 
With regards to decisions about knowledge sharing in a virtual community to gain advantage, people will choose different "strategies" in knowledge sharing based upon their different positions in the network. When previously possessing higher centrality in the knowledge network of a certain virtual community, participants can obtain more benefits such as interpersonal relationships, reputation, being recognized as an expert and being trusted, while other members rely on these leading members to communicate (Liu and Lin, 2015). With such previous advantages, willingness to share knowledge should be a certainty. If a member has achieved prior higher centrality in a knowledge network, he is likely more confident in social intercourse and knowledge sharing in the current knowledge network. Moreover, the individual in a position of higher centrality is more likely to be recognized by other members in knowledge transferring and learning. Their opinions will also be spread out and be referred to by other members before delivering their own opinions. Therefore, the higher the previous centrality of a member was, the more likely it will lead to a high frequency of current sharing behavior.

H3a: In a dynamic virtual community, previous individual centrality has a positive effect on the current frequency of knowledge sharing.

However, social exchange theory indicates that when individuals feel that their knowledge sharing behaviors are recognized or appreciated by the organization, they prefer to increase feedback about valuable knowledge and expect to get better returns (Sharon and Kelly, 2006). With previous high centrality, participants prefer to share knowledge to gain wider social media effects and social benefits. Schrader (1995) found that individual knowledge sharing behavior was influenced by the expectation of individuals for potential economic benefits after sharing. Bouty (2000) thinks that knowledge sharing behavior has characteristics of obvious social exchange, such as excitement due to reputation, power, reciprocity and other factors.

From a competition perspective, one will be cautious when sharing original knowledge, for instance, tacit knowledge, because it means losing the advantage based on such knowledge. However, original knowledge will have a wider social media effect and attract more social connections with the provider in a virtual community. Especially in a professional virtual community, original ideas and sharing shows the provider to be more creative and productive, which could bring more social capital, reputation, and also more opportunities for cooperation. In contrast, if a participant frequently shares second-hand knowledge and information in a certain virtual community, it will reduce his (or her) social cognition among all other community members.

In a dynamic and open knowledge network, individual original knowledge sharing behavior, in fact, has certain risks, including intellectual property disputes and competition caused by knowledge spillover. While in a dynamic knowledge network, previous point and node individual positions will affect the decision about original behavior. If the individual is on the edge of a previous point in the network, then he will have a much greater tendency to be a "free rider", and thus to refuse to share original, own, explicit or implicit knowledge. On the contrary, the individual would be more inclined to consolidate his social status and image in the knowledge community through original knowledge sharing behavior if he previously had higher centrality.

H3b: In a dynamic virtual community, previous individual centrality has a positive effect on the current originality of knowledge sharing. 


\section{Mediating effects of knowledge sharing behavior}

As mentioned above, the choice of individual knowledge sharing behavior is influenced by individuals previously embedded in a knowledge network, and the individual's current sharing behavior determines the individual embedding condition in the virtual community. The higher the level of node centrality of the individual, the higher the frequency of sharing behavior, further improving the degree of centrality of nodes in the current knowledge network of the virtual community. This creates a positive feedback loop: the higher the frequency of sharing behavior, the closer to the center of the dynamic network will the sharer be, and vice versa. In other words, individual behavior in the knowledge network will be influenced by previous benefits. This helps a knowledge community in the short term, but in the long run, it is likely to lead to an over-centralized virtual community.

H4a: In a dynamic knowledge network, the current frequency of knowledge sharing plays a mediating role between previous individual centrality and current individual centrality.

Similar to the frequency of knowledge sharing behavior, individual original knowledge sharing behavior in a dynamic virtual community also plays a mediating effect between previous and current positions characteristic of the virtual community. Previous individual centrality in the virtual community will promote original knowledge sharing selection at the current time, while original knowledge sharing will further contribute to the current centrality of the individual in the knowledge network. That means, in order to consolidate and seek a higher level of centrality, an individual with a higher level of centrality prefers to share original knowledge.

H4b: In a dynamic knowledge network, the current sharing of original knowledge plays a mediating role between previous individual centrality and current individual centrality.

\section{Research design: Network analysis of an online community from the Chinese consulting industry}

\section{Availability of data and materials}

We integrate all the hypotheses above and create a theoretical model of individual knowledge sharing behavior in a dynamic virtual community, as seen in Fig. 1. All data collection and variables measurements correspond to Fig. 1.

Virtual knowledge communities are popular these days, many of them with a certain hierarchical structure, measured and analyzed by many scholars (Chen and Hung, 2010). In recent years there are more and more inter-person virtual communities in China, with most of them on QQ or WeChat platforms, while others, especially knowledge exchange and consulting networks, use $\mathrm{C} 2 \mathrm{C}$ platforms such as Call Me.com. We selected a QQ professional group for our sample. We chose the online community "CMKT Management Club 2 Community" (QQ No. 51172158, hereinafter referred to as CMKT) of the CMKT Management Consulting Club, which is the largest professional virtual community for the management consulting industry in China.

Established in 2013, the CMKT satisfies most of the assumptions for our study: 1) Inter-person- all members of this QQ group comes from different well-known domestic management consulting firms, institutions and universities, and more than $80 \%$ work 


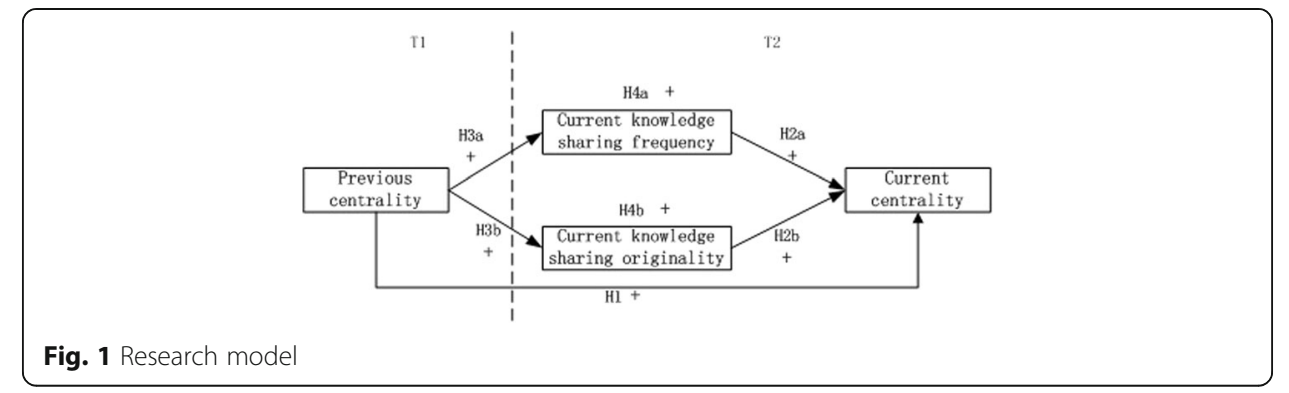

in Beijing, Shanghai, Guangzhou, Shenzhen and other central cities; 2) Knowledge inter-activities- discussions in this QQ group have been well managed, so that only relevant professional and consultant information or knowledge is shared, exchanged, and discussed in this virtual community. Thus we regard this QQ group as a representative sample for our study. All the data and materials in this research are collected from public information about the CMKT.

\section{Data collection}

We collected all QQ chat records from the CMKT community in March 2016 (from 0:00 March 1st to 0:00 April 1st). Because of the strict management of the community (no irrelevant information and advertising), CMKT only shares and communicates managerial consulting professional topics in daily chats. The knowledge exchange events of the CMKT community in March total 4866 posts, an average of 156.96 posts a day, in which non-original forwarding information stands at 16, a total of 123,518 words. In addition to the text, individuals delivered pictures, QQ expressions and others. These knowledge-sharing actions are this study's target of observation and measurement. The CMKT community also uploaded more than $156 \mathrm{M}$ files in March. However, the upload file information in the knowledge community may not have immediate feedback in the knowledge network. Therefore, it is excluded from sample data for the analysis.

\section{The coding of knowledge sharing behavior data}

In this paper, we take "day" as the observation time span, a total of 31 time periods. By collecting, organizing, identifying and coding the exchange information, we build a picture of the knowledge sharing behavior data in the CMKT. Specifically, the chat messages are encoded as follows: 1) the speaker's name, 2) the time the speech was posted (precise to seconds), 3) the form of the statement, and 4) the speech-related party (reply, @, etc.). Among them, the specific form of speech is divided into three types: text, forwarding, expression. If a specific chat record contains any of the above three forms of content, then the corresponding category code is 1 , otherwise, the code is 0 . The speech-related party refers to the association of a particular statement with other speakers of the day, consisting of both replies to other speeches earlier in the day and the next person to reply after the speech. We judge and identify the situation to which the statement responds or is responded to, by the contextual relevance of other speeches within a coherent time (30 min before and after). In a longer period of time after the speech, we collect and identify those who are clearly "@” the speaker, or 
include a review, to repeat the speech content of the speech situation and record the name of the community member associated with the statement and the frequency of the response to the statement.

In this paper, we establish a knowledge sharing behavior database of "each community member per day" and use UCINET software to analyze and calculate the data. It is not difficult to find that, although there are nearly 2000 members of the CMKT community, the participation in knowledge sharing is much less. In order to ensure the validity of the data and avoid interference and statistical errors caused by lack of data for the statistical analysis and model fitting, we only conduct an empirical analysis of the 10 most active members of the month. Those ten members had posted a total of 2960 times in March, which accounts for $60.83 \%$ of the posts in CMKT. Using "each community members per day" as a sample unit, we in the end collected 143 effective samples.

\section{Variable design}

\section{The dependent variable}

In this paper, the node centrality of the community members in the daily knowledge network is the dependent variable in the empirical study. Node centrality can reflect the popularity of individuals of the community in the network (Bulte and Wuyts, 2007), which is often used to measure location, status, reputation, etc. (Sparrowe et al., 2001). By inputting all the knowledge sharing behavior in the CMKT community and its associated data into UCINET software, we coded and analyzed the social network of knowledge sharing in each day of March, and calculated the node centrality of the 10 most active members in a day.

\section{The independent variable}

In this paper, the node centrality of the community members in the previous knowledge network is the independent variable in the empirical study. The independent variable is calculated in a similar manner to the dependent variable, but the previous node centrality of the day is calculated by taking the node centrality of the 10 most active members of the knowledge network from the previous day. The previous node centrality of March 1st is the knowledge network node centrality of the 10 most active members at the end of February.

\section{The mediating variable}

In this paper, the frequency and originality of individual sharing behavior is the intermediary variable. The frequency of communication can be used for judging the relationship between individuals. In the knowledge network, frequent exchanges between individuals are conducive to knowledge sharing and exchange (Szulanski, 1996), while the lower exchange is beneficial for contact with new information and access to new knowledge for individuals. "Frequency" in this paper refers to the total number of posts in the same day.

In a community, the individual may worry that his own original knowledge will lose its unique value (Empson, 2001), but if members are not willing to share original knowledge, then the knowledge network will fail (Zárraga and Bonache, 2003). In this paper, we measure the degree of originality by calculating the ratio of post frequency to different ways of sharing, and the formula is originality = text post frequency/(forwarding frequency + expression frequency). 


\section{The control variables}

Network cognition and personal reputation (Zhang et al., 2017) and experience (Wang et al., 2011) are found to influence network position (Reinholt and Foss, 2011) and knowledge sharing (Liao et al., 2013). Thus the practitioner's time of joining, and the valuation by the QQ center is used as a control variable. In this paper, we measure the time of joining the knowledge network as a proxy for members' career experience. The QQ valuation refers to an integrative valuation by QQ center of all online activities in all QQ website, communicating software, blogs, and WeChat. Thus QQ valuation can be regarded as a measurement of individual personality traits.

\section{Analysis result}

\section{Dynamics of virtual community}

Figure 2 shows the social network topology of knowledge sharing behavior for all members of the CMKT network in March. We can see that the network has formed a number of "centers", but at the same time, some nodes do not interact with any others. The knowledge network shown in Fig. 2 is still static.

Observing the knowledge network (Fig. 3) of CMKT for 1 day, we find two prominent features: one is dynamism. Although there are a great number of members in the online community, not every member is engaged in information exchange at all times. The subjects of discussions differ over time. Therefore, the actual participants in the CMKT community each day are dynamic: the knowledge sharing among the members who participate in the discussion varies in frequency and manner every day; the knowledge social network between members differs in scale, density, and structure. The dynamism is illustrated in Fig. 3 for only 4 days in March. Another is openness. In online communities, members either quit (either voluntarily opt out or are banned for violations) or join every day. The most active knowledge sharing behavior is not always from the 10 most active members in March every day. Every day the members of the knowledge network are not fixed, and the central node in the knowledge network is not limited to one or a few people. In such a knowledge network community, we find that some individuals have a relatively clear pattern of knowledge sharing behavior, which can be defined as a sharing

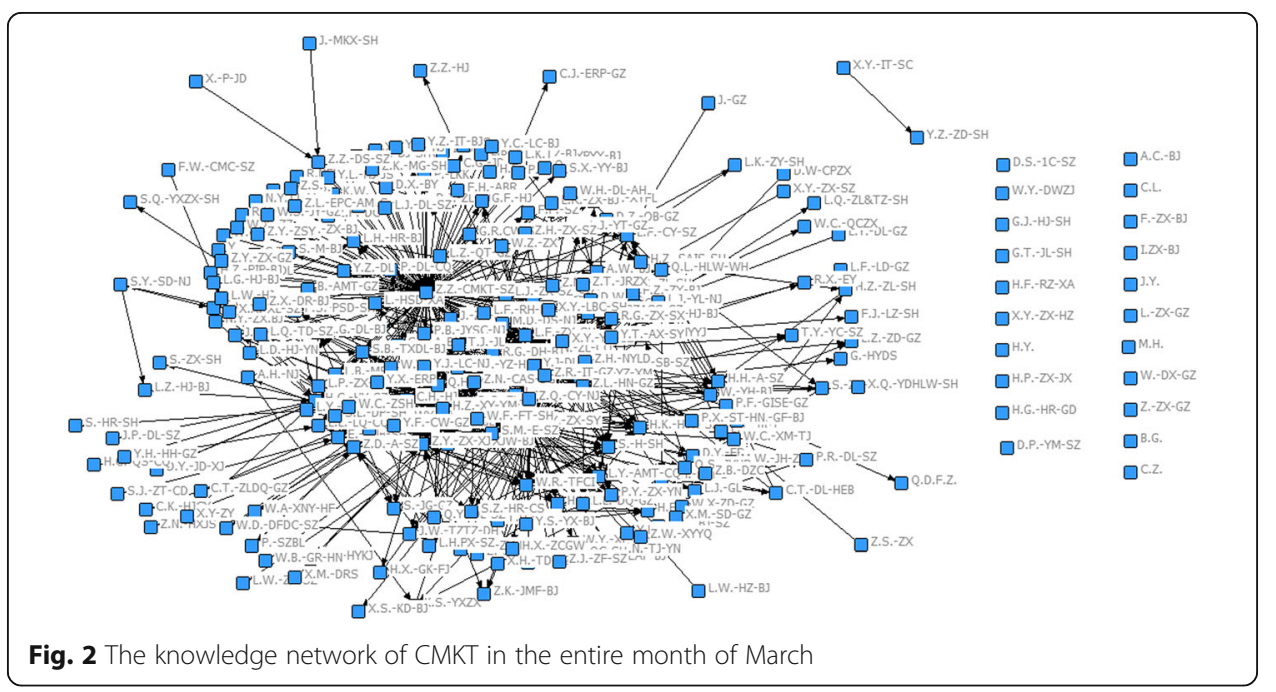


strategic choice. Some individuals have a strong sensitivity to the "discourse power" of certain topics in the community and they will immediately join in the discussion as long as the community members are involved in the topic. Some individuals regularly forward some networks (such as weather forecasts or newsletters) every day, regardless of the response. In various kinds of knowledge sharing strategies, this paper is concerned with whether frequency and originality help to enhance the status and importance of a dynamic and open knowledge network.

\section{Results of regressions}

In order to verify the mediating effect model, we analyzed the online knowledge sharing behavior data of the 10 most active members of CMKT and calculated their daily knowledge network node centrality data using UCINET software. By incorporating the data into SPSS 16.0, we carried out correlation analysis and linear regression analysis. (Table 1).

Table 2 shows the regression analysis results of the mediation effect stepwise test (Baron and Kenny, 1986). The $R^{2}$ adjustment and $F$ test of all the models are in a reasonable range, indicating that the fitting degree of all regression models is acceptable.

In Model 1, the previous centrality has significant positive effects on current centrality $(0.479, p<0.001), \mathrm{H} 1$ is supported. This result supports the network effects theory, in a dynamic virtual community, even if the structure and participants in the virtual community knowledge network changes over time, there are still "snowball effects" (Schilling, 2002).

In Model 2 and Model 3, the frequency and originality of individual sharing behavior have significant positive effects on the centrality of the current network $(0.753, p<$ 0.001 in Model 2; 0.732, $p<0.001$ in Model 3), therefore H2a and H2b are supported. It indicates that the sharing behavior of the individual in a virtual community has a direct effect on his (or her) position in the network.

In Model 4 and Model 5, the previous centrality plays significant positive roles on the frequency and originality of current knowledge sharing behavior $(0.301, p<0.01$ in

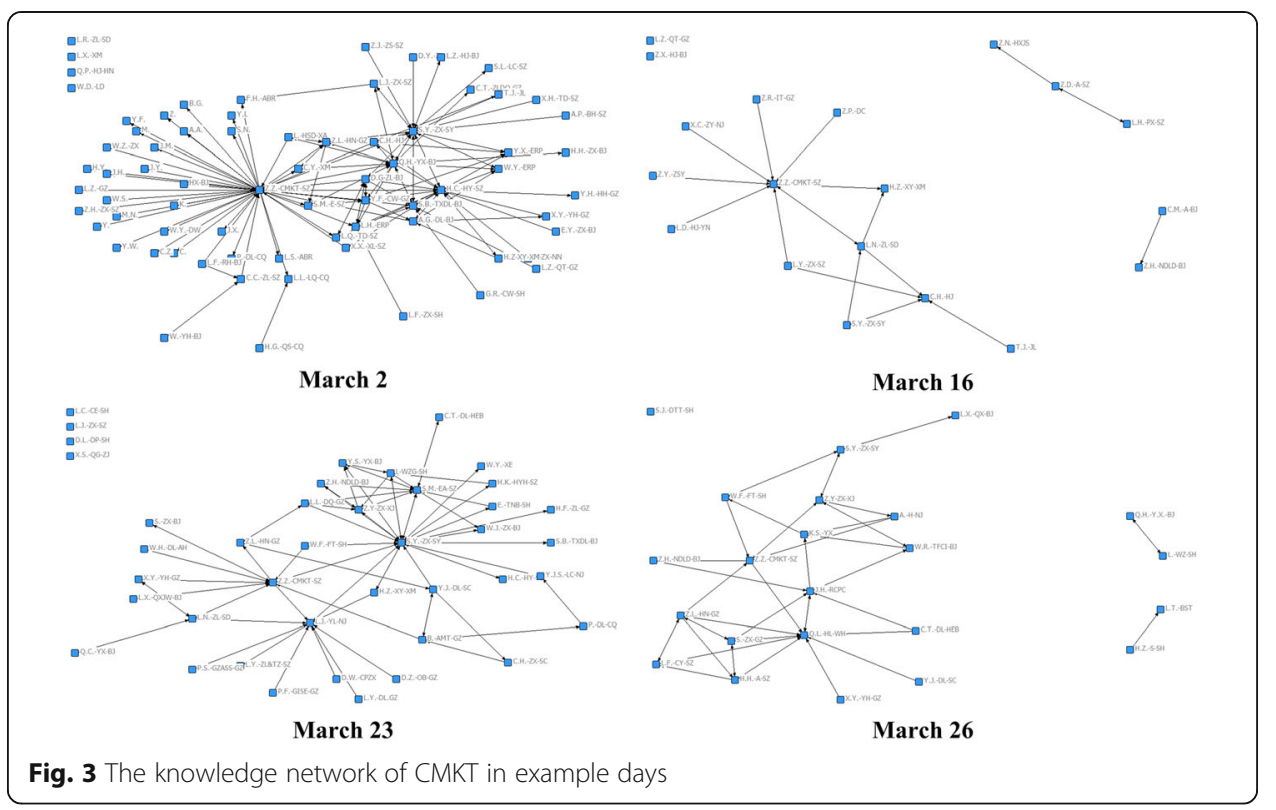


Table 1 Descriptive statistics and correlation analysis

\begin{tabular}{lllllllll}
\hline & Mean & standard deviations & 1 & 2 & 3 & 4 & 5 \\
\hline 1 frequency & $2.004895 \mathrm{E} 1$ & 33.5641762 & 1 & & & & \\
2 originality & $1.807699 \mathrm{E} 1$ & 33.0340739 & $.998^{* *}$ & 1 & & & \\
3pre- centrality & 4.1748 & 5.12425 & $.189^{*}$ & $.180^{*}$ & 1 & & \\
4 centrality & 4.5944 & 5.34742 & $.754^{* *}$ & $.733^{* *}$ & $.289^{* *}$ & 1 & \\
5 time & 7.35 & 2.37253 & .189 & $.325^{*}$ & .102 & $.225^{*}$ & 1 \\
6 Evalu. & $-7.9501285 \mathrm{E}-16$ & 1.00000000 & $.228^{* *}$ & $.179^{*}$ & .092 & $.345^{* *}$ & $.189^{*}$ \\
\hline$*: p<0.5 ; * *: p<0.01 ;^{* * *}: p<0.001$ & & & & & & &
\end{tabular}

Model 4; 0.281, $p<0.05$ in Model 5), therefore H3a and H3b are accepted. It indicates that the higher the individual center level was previously in the virtual community network, the higher the current frequency and originality of the knowledge sharing behavior in the virtual network. In other words, the prior position of the individual in the network will determine current knowledge sharing behavior.

In Model 6 and Model 7, the frequency and originality of individual sharing behavior have significant positive effects on centrality under the premise that the model which controlled the prior centrality $(0.709, p<0.001$ in Model 6; 0.688, $p<0.001$ in Model 7). Along with Model 1, 4 and 5, according to the criteria of the mediating effect (Baron and Kenny, 1986), H4a and H4b are supported. In a dynamic virtual community, the frequency and originality of individual sharing behavior play incomplete mediating roles between previous and current centrality. The previous position of the individual in the network will affect current knowledge sharing behavior, and thus affect the status of the current network.

\section{Robustness test}

To check the robustness of our findings, we tested a larger set of samples and a wider time period in two ways. Firstly, we collected data in 3 months- March, April and May in 2016, also from the "CMKT Management Club 2 community", and measured all variables by a time unit of 1 week. Secondly, we collected data from the CMKT Management Club Wechat group. We wondered if there were different situations and rules for the same virtual community on different online platforms. We collected the data from the CMKT Wechat group in March 2016. Both analyses had similar findings.

\section{Discussion and conclusion}

The discussion of analysis results

A virtual community based on knowledge sharing and exchange forms a social network for communication, exchange, and sharing of knowledge and information. Though the structure, participation, and actions in a virtual community are dynamic, few scholars of knowledge networks have highlighted the dynamic nature of knowledge networks. Gong (2011) argued that knowledge sharing and interaction between individuals or organizations in the knowledge network were dynamic. Butts (2011) thought that any social network (including a knowledge network) is dynamic over time. In this paper, we examine the deeper nature of the dynamic nature of the knowledge network: 1) The network members are dynamic, and they (nodes) change in the knowledge network at 
Table 2 Results of regression analysis

\begin{tabular}{|c|c|c|c|c|c|c|c|}
\hline & $\begin{array}{l}\text { Model } 1 \\
\text { centrality }\end{array}$ & $\begin{array}{l}\text { Model } 2 \\
\text { centrality }\end{array}$ & $\begin{array}{l}\text { Model } 3 \\
\text { centrality }\end{array}$ & $\begin{array}{l}\text { Model } 4 \\
\text { frequency }\end{array}$ & $\begin{array}{l}\text { Model } 5 \\
\text { originality }\end{array}$ & $\begin{array}{l}\text { Model } 6 \\
\text { centrality }\end{array}$ & $\begin{array}{l}\text { Model } 7 \\
\text { centrality }\end{array}$ \\
\hline Constant & $(6.299)^{* * *}$ & $(2.521)^{* *}$ & $(6.162)^{* * *}$ & $(4.268)^{* * * *}$ & $(3.845)^{* * *}$ & $(4.376)^{* * *}$ & $(4.821)^{* * * *}$ \\
\hline Time & $\begin{array}{l}.217^{*} \\
(.859)\end{array}$ & $\begin{array}{l}.272^{*} \\
(.977)\end{array}$ & $\begin{array}{l}.261^{*} \\
(1.105)\end{array}$ & $\begin{array}{l}.192 \\
(.633)\end{array}$ & $\begin{array}{l}.337 \\
(1.021)\end{array}$ & $\begin{array}{l}.365 \\
(3.259)\end{array}$ & $\begin{array}{l}.271 \\
(2.797)\end{array}$ \\
\hline Evalu. & $\begin{array}{l}.234 \\
(1.014)\end{array}$ & $\begin{array}{l}.243^{*} \\
(1.232)\end{array}$ & $\begin{array}{l}.252 \\
(1.012)\end{array}$ & $\begin{array}{l}.208 \\
(0.976)\end{array}$ & $\begin{array}{l}.152 \\
(0.838)\end{array}$ & $\begin{array}{l}.267 \\
(1.254)\end{array}$ & $\begin{array}{l}.199 \\
(1.843)\end{array}$ \\
\hline Pre- centrality & $\begin{array}{l}.479^{* * *} \\
(4.516)\end{array}$ & & & $\begin{array}{l}.301^{* *} \\
(2.724)\end{array}$ & $\begin{array}{l}.281^{*} \\
(2.534)\end{array}$ & $\begin{array}{l}.265^{* * *} \\
(3.609)\end{array}$ & $\begin{array}{l}.286^{* * *} \\
(3.779)\end{array}$ \\
\hline Frequency & & $\begin{array}{l}.753^{* * *} \\
(13.555)\end{array}$ & & & & $\begin{array}{l}.709^{* * *} \\
(12.955)\end{array}$ & \\
\hline Originality & & & $\begin{array}{l}.732^{* * *} \\
(12.722)\end{array}$ & & & & $\begin{array}{l}.688^{* * *} \\
(12.225)\end{array}$ \\
\hline$R^{2}$ adj. & .116 & .642 & .530 & .038 & .031 & .597 & .571 \\
\hline F value & $10.299^{* * *}$ & $86.021^{* * *}$ & $81.116^{* * *}$ & $3.795^{*}$ & $3.309^{*}$ & $70.994^{* * *}$ & $63.967^{* * *}$ \\
\hline
\end{tabular}

*: $p<0.5 ;{ }^{* *}: p<0.01 ; * * *: p<0.001$

The $t$-value test in bracket

different times; 2) The network association is dynamic. Knowledge, as an intangible resource, can freely flow, transfer, reproduce and innovate, and may be dynamic as a form of association between social subjects in different observation periods. 3) The network structure is dynamic. Since the network members are dynamic, so is the association between knowledge sharing, transferring and reproduction. Therefore, the structure of the knowledge network is also dynamic in different periods. 4) Individual knowledge sharing behavior in the knowledge network is dynamic. Each network member can dynamically analyze the behavior of other participants at different points in time, and make decisions accordingly including whether to participate in sharing behavior, as well as analyze specific strategic options, such as knowledge sharing frequency or originality.

In a dynamic virtual community knowledge network, individual knowledge sharing behavior is decided by participants taking into account various personal goals, including establishing and consolidating social status, and increasing social capital in the knowledge community. In an inter-person virtual community, thus, knowledge sharing behaviors of members contribute to improving status to gain advantages. The behavior of the individual in the dynamic knowledge network should be measured in a continuous time dimension. Based on the theory of network effects and competition, we found that frequency and originality are both effective methods of knowledge sharing behavior that help build higher centrality in such dynamic virtual communities.

We further demonstrate that individual knowledge sharing behavior is related to the dynamic evolution of the individual's position in the dynamic knowledge network. The position (node centrality) of an individual in a previous time period determines the knowledge sharing behavior in the current time period, including frequency and originality, and vice versa. This mechanism can be called the "inertia effect", more or less similar to a kind of "path dependency". The "inertia effect" of individual knowledge sharing behavior strongly shapes the evolution of the virtual community. Contrary to a member with high centrality in the virtual community, those on the edge of the knowledge network will be more marginalized. Ultimately, this virtual community will develop toward a state of "one talker only" or mostly "silent". This process is consistent with economists' views on network effect theory, such as "winner-take-all" and "snowball" effects (Stabell and 
Fjeldstad, 1998). The direction of the evolution, though, driven by individual behavior is not conducive to the overall interests of a virtual community, especially for online learning and collaborative innovation (Koh, et al., 2007). This paper carries out a dynamic network analysis of knowledge sharing behavior, providing a perspective to collect structured and unstructured data, analyze and predict the dynamic evolution, to help manage such virtual communities.

\section{Conclusion and limitation}

In the dynamic virtual community, the direct result of knowledge sharing behavior is reflected in the individual position (the degree of node centrality). Moreover, the individual knowledge sharing behavior has an "inertia effect": individual previous status (the degree of node centrality) affects current knowledge sharing behavior, while current knowledge sharing behavior affects the current status in the knowledge network, forming an inertial circuit between personal behavior and network status.

This study has the following theoretical contributions:

1) This study expands the theory of individual knowledge sharing in the context of inter-person dynamic virtual communities. Knowledge sharing has been regarded as just a method to contribute to organizational innovative performance for a long time (Carmeli et al., 2013). Although some scholars have found that knowledge sharing behavior is embedded in an inter-person social network, e.g. an employee community (Yong, et al., 2013) or a global innovative group (Olaisen and Revang, 2017), knowledge sharing behavior is examined only as an organizational decision. This study is interested in the individual goals of sharing behavior. By answering a fundamental question of "what kind of sharing action could help build the personal advantage in the community", this study explores the mechanism of knowledge sharing behavior as an individual decision.

2) This study provides action "strategies" for individual knowledge sharing behavior choice, for better understanding the nature of individual knowledge behavior. Scholars have considered the behavior of knowledge sharing as a "black box", and have seldom looked into and explored the categories of knowledge sharing behavior. While most literature has focused on the motivations or antecedents of knowledge sharing, this study focuses on examining two characteristics of knowledge sharing behavior, frequency and originality. Moreover, this study considers frequency and originality as two "strategies" of knowledge sharing for building the personal advantage in a virtual community and looks at the inter-relationship with network position in a dynamic virtual community.

3) This study proposes and tests the "inertia effect" of knowledge sharing behavior and the knowledge network, and the theory of network effects from an individual perspective. Network effect theory holds that organizations or individuals in the center will continue to acquire more network effects with the evolution of network structure. However, it cannot be accurately predicted who may continually hold the center position in the network or whether the network externalities will be eventually regarded as a resource or constraints to achieve Pareto Optimality (Kumar and Sastry, 2013) for all participants. In a dynamic virtual community, the 
"inertia effect" of behavior resulting from individual analysis demonstrates the network effect theory at the micro level of the individual and makes it possible to describe the evolution of the network effect from the individual behavior level. Based on the "inertia effect" of individual sharing behavior, people can track and even predict the evolution of a knowledge community through this mathematical model.

This paper has the following limitations:

1) Due to the shortage of time, the sample selection in this paper only tested the data generated by a professional knowledge community for one a month and lacks validation from multiple data sets. The resulting sample data is not able to compare different types of knowledge communities and networks, and does not reflect the differences between sectors. 2) This paper focuses on online individual behavior, and does not consider the effects of knowledge sharing motivation and behavioral decision-making on individual behavior in the real world. 3) In this paper, we tested the "inertia effect" between knowledge sharing and network position dynamics only by the originality and frequency of sharing behavior. Further research on other categories of knowledge sharing behavior is needed.

Abbreviations

CMKT: CMKT Management Club 2 community

Acknowledgements

We appreciate CMKT Management Consulting Club for its help in collecting raw data for this paper.

Funding

Key project of philosophy and social science research of Ministry of Education (No. 15JZD020).

\title{
Authors' contributions
}

PS designed the research, carried on the empirical modeling and audited the draft. CW helped coding data, ran the network index with UCINET, and made the figures in the draft and reference as well. Both authors read and approved the final manuscript.

Competing interests

The authors declare that they have no competing interests.

\section{Publisher's Note}

Springer Nature remains neutral with regard to jurisdictional claims in published maps and institutional affiliations.

\author{
Author details \\ ${ }^{1}$ School of Management, Guagnzhou University, Guangzhou, Guangdong 510410, China. ${ }^{2}$ Great Wall Strategy \\ Consultants, Beijing 100101, China.
}

Received: 27 July 2017 Accepted: 6 December 2017

Published online: 19 December 2017

\section{References}

Almeida, M. V., \& Soares, A. L. (2014). Knowledge sharing in project-based organizations: overcoming the informational limbo. International Journal of Information Management, 34(6), 770-779.

Anderson, M. H. (2008). Social networks and the cognitive motivation to realize network opportunities: a study of managers' information gathering behaviors. Journal of Organizational Behavior, 29(1), 51-78.

Arroyo, J. L. (2007). Externalidades de red en la economia digital. Madrid: Fundacion Rafael del Pino and Marcial Pons.

Avital, M., \& Singh, B. (2007). The impact of collaboration and competition on project performance, International conference on information systems (p. 89).

Barão, A., Vasconcelos, J. B. D., Rocha, Á., \& Pereira, R. (2017). A knowledge management approach to capture organizational learning networks. International Journal of Information Management. Processing, 37(5), 735-740.

Baron, R. M., \& Kenny, D. A. (1986). The moderator-mediator variable distinction in social psychological research: conceptual, strategic, and statistical considerations. Journal of Personality and Social Psychology, 51(6), 1173-1182.

Bij, H. V. D., Song, X. M., \& Weggeman, M. (2003). An empirical investigation into the antecedents of knowledge dissemination at the strategic business unit level. Journal of Product Innovation Management, 20(2), 163-179.

Bock, G. W., Zmud, R. W., Kim, Y. G., \& Lee, J. N. (2005). Behavioral intention formation in knowledge sharing: examining the roles of extrinsic motivators, social-psychological factors, and organizational climate. MIS Quarterly, 29(1), 87-111. 
Bouty, I. (2000). Interpersonal and interaction influences on informal resource exchanges between R\&D researchers across organizational boundaries. Academy of Management Journal, 43(1), 50-65.

Bulte, C., \& Wuyts, S. (2007). Social networks in marketing. Cambridge: Marketing Science Institute.

Burt, R. S. (1992). Structural holes: The social structure of competition. Cambridge: Harvard University Press.

Butts, C. T. (2011). Bayesian meta-analysis of social network data via conditional uniform graph quantities. Sociological Methodology, 41(1), 257-298.

Cai, S., Goh, M., Souza, R., \& Li, G. (2013). Knowledge sharing in collaborative supply chains: twin effects of trust and power. International Journal of Production Research, 51(7), 2060-2076.

Carmeli, A., Gelbard, R., \& Reiter-Palmon, R. (2013). Leadership, creative problem-solving capacity, and creative performance: the importance of knowledge sharing. Human Resource Management, 52(1), 95-121.

Chen, C. J., \& Hung, S. W. (2010). To give or to receive? Factors influencing members' knowledge sharing and community promotion in professional virtual communities. Information Management, 47(4), 226-236.

Economides, N., \& Himmelberg, CP. (1995). Critical mass and network size with application to the US FAX market. Working papers.

Empson, L. (2001). Fear of exploitation and fear of contamination: impediments to knowledge transfer in mergers between professional service firms. Human Relations, 54(7), 839-862.

Freeman, L. C. (1979). Centrality in social networks: conceptual clarification. Social Networks, 1(3), 215-239.

Gong, B. (2011). Individual and collective inter-organizational Guanxi: the dynamics of Guanxi, and knowledge sharing. Frontiers of Business Research in China, 5(4), 473-489.

Gupta, S., \& Polonsky, M. (2014). Inter-firm learning and knowledge-sharing in multinational networks: an outsourced organization's perspective. Journal of Business Research, 67(4), 615-622.

He, W., \& Wei, K.-K. (2009). What drives continued knowledge sharing? An investigation of knowledge-contribution and -seeking beliefs. Decision Support Systems, 46(3), 826-838.

Hendriks, P. (2015). Why share knowledge? The influence of ICT on the motivation for knowledge sharing. Knowledge \& Process Management, 6(2), 91-100.

Hsu, M.-H., Ju, T. L., Yen, C.-H., \& Chang, C.-M. (2007). Knowledge sharing behavior in virtual communities: the relationship between trust, self-efficacy, and outcome expectations. International Journal of Human-Computer Studies, 65(2), 153-169.

Jiang, L. (2015). Method of dynamic pattern mining based on complex network. Hebei: Yan Shan University (In Chinese).

Kang, Y. J., Jin, Y. L., \& Kim, H. W. (2017). A psychological empowerment approach to online knowledge sharing. Computers in Human Behavior, 74, 175-187.

Katz, M. L., \& Shapiro, C. (1985). Network externalities, competition, and compatibility. American Economic Review, 75(3), 424-440.

Koh, J., Kim, Y. G., Butler, B., \& Bock, G. W. (2007). Encouraging participation in virtual communities. Communications of the $A C M, 50(2), 68-73$

Kumar, M. K., \& Sastry, V. N. (2013). A new algorithm to compute Pareto-optimal paths in a multi objective fuzzy weighted network. Opsearch, 50(3), 297-318.

Li, X. (2005). New basic psychology. Nanjing: Nanjing Normal University Press (In Chinese).

Liao, C., To, P. L., \& Hsu, F. C. (2013). Exploring knowledge sharing in virtual communities. Online Information Review, 37(6), 891-909.

Lin, B. (2007). The effects of cross-functional cooperation and competition on new product performance: How does knowledge management processes matter? Hong Kong: City University of Hong Kong.

Lin, Q., et al. (2014). A longitudinal and multilevel investigation on factors influencing knowledge sharing behavior. Journal of Management Policy and Practice., 15(3), 88-101.

Lin, S. P., Wang, Y. C., Tsai, Y. H., \& Hsu, Y. F. (2010). Perceived job effectiveness in coopetition: a survey of virtual teams within business organizations. Computers in Human Behavior, 26(1), 1598-1606.

Liu, P., \& Lin, R. P. (2015). Research on knowledge sharing and dissemination behavior of Online Q \& a Services: Taking Zhihu as an example. Documentation, Information \& Knowledge, 6, 109-119 (In Chinese).

Loebecke, C., Van Fenema, P. C., \& Powell, P. (1999). Co-opetition and knowledge transfer. The Database for Advances in Information Systems, 30(2), 14-25.

Lorange, P. (1996). Strategy at the leading edge-interactive strategy-alliances and partnership. Long Range Planning, 29(4), 581-584.

Luo, X., Slotegraaf, R. J., \& Pan, X. (2006). Cross-functional coopetition: the simultaneous role of cooperation and competition within firms. Journal of Marketing, 70(1), 67-80.

Ma, G., Q., Xu, Q., Liao, Z. P., \& Zhang, C. J. (2006). Analyze on the infection factor of knowledge transfer. Science Research Management, 27(3), 50-54 (In Chinese).

Mishina, Y., Block, E. S., \& Mannor, M. J. (2012). The path dependence of organizational reputation: How social judgment influences assessments of capability and Charater. Strategic Management Journal, 33(5), 459-477.

Nahapiet, J., \& Ghoshal, S. (1998). Social capital, intellectual capital, and the organizational advantage. Academy of Management Review, 23(2), 242-266.

Olaisen, J., \& Revang, O. (2017). Working smarter and greener: collaborative knowledge sharing in virtual global project teams. International Journal of Information Management, 37(1), 1441-1448.

Organ, D. W., \& Lingl, A. (1994). Personality, satisfaction, and organizational citizenship behavior. Journal of Social Psychology, 135(3), 339-350.

Park, J. G., \& Lee, J. (2014). Knowledge sharing in information systems development projects: explicating the role of dependence and trust. International Journal of Project Management, 32(1), 153-165.

Qiu, J., \& Wang, F. (2011). Analysis about knowledge communication network based on friends link in the blog community-a case study of the blog community in www.sciencenet.cn. Document, Information \& Knowledge, 6, 25-33 (In Chinese).

Reinholt, M., \& Foss, N. J. (2011). Why a central network position isn't enough: the role of motivation and ability for knowledge sharing in employee networks. Academy of Management Journal., 54(6), 1277-1297.

Ritala, P., Olander, H., Michailova, S., \& Husted, K. (2015). Knowledge sharing, knowledge leaking and relative innovation performance: an empirical study. Technovation, 35, 22-31. 
Saifi, S. A. A., Dillon, S., \& Mcqueen, R. (2016). The relationship between face to face social networks and knowledge sharing: an exploratory study of manufacturing firms. Journal of Knowledge Management, 20(2), 308-326.

Schilling, M. A. (2002). Technology success and failure in winner-take-all market: the impact of learning orientation, timing, and network externalities. Academy of Management Journal, 45(2), 387-398.

Schrader, S. (1995). Gaining advantage by 'leaking' information: Informal information trading. European Management Journal, 13(2), 156-163.

Sharon, W., \& Kelly, H. (2006). A multi-theoretical model of knowledge transfer in organizations: determinants of knowledge contribution and knowledge reuse. Journal of Management Studies, 43(2), 141-173.

Sparrowe, R. T., Liden, R. C., \& Wayne, S. J. (2001). Social networks and the performance of individuals and groups. Academy of Management Journal, 44(2), 316-325.

Stabell, C. B., \& Fjeldstad, Ø. D. (1998). Configuring value for competitive advantage: on chains, shops, and networks. Strategic Management Journal, 19(5), 413-437.

Szulanski, G. (1996). Exploring internal stickiness: impediments to the transfer of best practice within the firm. Strategic Management Journal, 17(2), 27-43.

Torrent-Sellens, J. (2015). Knowledge products and network externalities: Implications for the business strategy. Journal of Knowledge Economics, 6(1), 138-156.

Tsai, W. (2001). Knowledge transfer in intraorganizational networks: effects of network position and absorptive capacity on business unit innovation and performance. Academy of Management Journal, 44(5), 996-1004.

Tsai, W. (2002). Social structure of 'coopetition' within a multiunit organization: coordination, competition, and intraorganizational knowledge sharing. Organization Science, 13(2), 179-190.

Tsai, W., \& Ghoshal, S. (1998). Social capital and value creation: the role of intrafirm networks. Academy of Management Journal, 41(4), 464-476.

Wang, S., Noe, R. A., \& Wang, Z. M. (2011). Motivating knowledge sharing in knowledge management systems: a quasi-field experiment. Journal of Management, 40(4), 978-1009.

Wang, X. L. (2014). Social influence of key opinion leaders in online community: a case study of Zhihu. Com. Chinese Journal of Journalism \& Communication, 9, 47-57 (In Chinese).

Wasko, M. L., \& Faraj, S. (2005). Why should i share? Examining social capital and knowledge contribution in electronic networks of practice. MIS Quarterly, 29(1), 35-57.

Wasserman, S., \& Faust, K. (1994). Social network analysis. New York: Cambridge University Press.

Wei, J. C., Liu, L., \& Francesco, C. A. (2009). A cognitive model of intra-organizational knowledge-sharing motivations in the view of cross-culture. International Journal of Information Management, 30(3), 220-230.

Weinberg, F. J. (2015). Epistemological beliefs and knowledge sharing in work teams: A new model and research questions. The Learning Organization, 22(1), 40-57.

Xue, H. B. (2011). An empirical study on the integration of network centrality and brand community into the social performance. Contemporary Finance \& Economics, 10, 73-81 (In Chinese)

Yang, H. L., \& Wu, T. C. T. (2008). Knowledge sharing in an organization. Technological Forecasting and Social Change, 75(8), 1128-1156

Yang, S. C., \& Farn, C. K. (2009). Social capital, behavioural control, and tacit knowledge sharing-A multi-informant design. International Journal of Information Management, 29(3), 210-218.

Yong, S. H., Kim, B., Lee, H., \& Kim, Y. G. (2013). The effects of individual motivations and social capital on employees' tacit and explicit knowledge sharing intentions. International Journal of Information Management, 33(2), 356-366.

Yoo, Y., \& Alavi, M. (2004). Emergent leadership in virtual teams: What do emergent leaders do? Information \& Organization, 14(1), 27-58.

Yu, T.-K., Lu, L.-C., \& Liu, T.-F. (2010). Exploring factors that influence knowledge sharing behavior via weblogs. Computers in Human Behavior, 26(1), 32-41.

Zárraga, C., \& Bonache, J. (2003). Assessing the team environment for knowledge sharing: An empirical analysis. International Journal of Human Resource Management, 14(7), 1227-1245.

Zhang, X., Liu, S., Deng, Z., \& Chen, X. (2017). Knowledge sharing motivations in online health communities: A comparative study of health professionals and normal users. Computers in Human Behavior, 75, 797-810 (In Chinese).

Zhang, Y., Fang, Y., Wei, K. K., et al. (2010). Exploring the role of psychological safety in promoting the intention to continue sharing knowledge in virtual communities. International Journal of Information Management, 30(5), 425-436.

Zhang, Z. G., Li, J. J., \& Li, Y. J. (2014). The innovation behavior of knowledge workers: The role of organizational learning and knowledge sharing. Science \& Technology Progress and Policy, 20, 126-131 (In Chinese).

Zhou, K. Z., \& Li, C. B. (2012). How knowledge affects radical innovation: Knowledge base, market knowledge acquisition, and internal knowledge sharing. Strategic Management Journal, 33(9), 1090-1102.

Zhou, Z. M., Zhang, J. L., \& Xiong, Y. P. (2014). How do introversion-extraversion personality traits influence knowledge sharing behavior in online brand communities: The mediation of network centrality and reciprocity norm. Nankai Business Review, 17(3), 19-29 (In Chinese). 